\title{
Experimental Testing for Stability Analysis of Distributed Energy Resources Components with Storage Devices and Loads
}

\author{
Mihet-Popa, Lucian; Groza, Voicu; Isleifsson, Fridrik Rafn
}

Published in:

Proceedings of IEEE Instrumentation/Measurement Technology Conference (I2MTC)

Link to article, DOI:

10.1109/I2MTC.2012.6229172

Publication date:

2012

Document Version

Peer reviewed version

Link back to DTU Orbit

Citation (APA):

Mihet-Popa, L., Groza, V., \& Isleifsson, F. R. (2012). Experimental Testing for Stability Analysis of Distributed Energy Resources Components with Storage Devices and Loads. In Proceedings of IEEE Instrumentation/Measurement Technology Conference (I2MTC) (pp. 588 - 593). IEEE. https://doi.org/10.1109/I2MTC.2012.6229172

\section{General rights}

Copyright and moral rights for the publications made accessible in the public portal are retained by the authors and/or other copyright owners and it is a condition of accessing publications that users recognise and abide by the legal requirements associated with these rights.

- Users may download and print one copy of any publication from the public portal for the purpose of private study or research.

- You may not further distribute the material or use it for any profit-making activity or commercial gain

- You may freely distribute the URL identifying the publication in the public portal 


\section{Experimental Testing for Stability Analysis of Distributed Energy Resources Components with Storage Devices and Loads}

\author{
Lucian Mihet-Popa, Fridrik Isleifsson \\ Electrical Engineering Department \\ RISO DTU, Denmark \\ lmih@risoe.dtu.dk
}

\begin{abstract}
The distributed energy resources (DER) contains several technologies, such as diesel engines, small wind turbines, photovoltaic inverters, etc. The control of DER components with storage devices and (controllable) loads, such as batteries, capacitors, dump loads, are central to the concept of the Micro Grids (MGs). A MG can operate interconnected to the main distribution grid or in islanded mode. This paper presents experimental tests for static and dynamic stability analysis carried out in a dedicated laboratory for research in distributed control and micro-grid with a high share of renewable energy production. Moreover to point out, on a laboratory scale, the coupling between DR and storage and to effectively compensate wind fluctuations a number of tests have been done. In order to find out the parameters of various types of DER components for dynamic simulation models a number of tests are required under different operation modes and loads. The testing reporting here includes three modes of operation: stand alone, parallel/hybrid and grid connection.
\end{abstract}

Keywords-distributed energy resources; micro-grid; static and dynamic stability analysis;

\section{INTRODUCTION}

Renewable energy systems are growing up due to not only environmental aspect but also due to social, economical and political interest. As the prevalence of renewable power grows increasing demand is being placed on maintaining grid stability and fulfilling grid codes.

One of the challenges of a smart grid is the ability to cope with intermittent and variable power sources, such as wind and solar, due to the variable nature of these systems [1-2].

The electrical power system is facing an evolution from the traditional concept of energy generation by few localized power plants interconnected together through a meshed system to distributed medium and small scale generators. Some topologies of these generators embedded into the distribution network are fed by renewable sources like wind and sunlight. Their main drawback is their hardly predictable behavior and uncontrollable output. The presence of energy storage system may allow a better management of the electric system allowing the full exploitation of renewable energy sources. Distribution companies start to recognize that storage has the unique ability

\author{
Voicu Groza \\ School of Information Technology and Engineering \\ University of Ottawa \\ Ottawa, Canada \\ groza@site.uottawa.ca
}

to act as a buffer between the grid and generation that is either intermittent or not controlled by the utility [2-5].

The distributed generation is taking importance pointing out that the future utility line will be formed by distributed energy resources and micro-grids. The flexible micro-grid has to be able to import/export energy from/to the grid, control the active and reactive power flows and manage of the storage energy [6].

With the publication of IEEE Standard for Interconnecting Distributed Resources with Electric Power Systems, the electric power industry has a need to develop tests and procedures for verifying that DER components meet the technical requirements [7].

This paper focuses on the static and dynamic performance and stability of DER components in Micro-Grids. Dynamic and transient events (wind variation, connecting/disconnecting sequence etc.) are studied as a basis for further activities in which the dynamic simulation models of DER components and other DG units and the related control systems capable of performing a coordinated management will be implemented. Also, in order to find out the differences between DER components in power systems and to study the impact on bus bar voltage and frequency the system will be tested for different wind speeds and loads.

\section{DISTRIBUTED ENERGY SYSTEM. EXPERIMENTAL FACILITY}

The SYSLAB is a laboratory for research in distributed control and smart grids with a high share of renewable energy production. Its experimental facility is a Wind/PV/Diesel Hybrid Mini-Grid with local storage and a novel control infrastructure. The facility is spread across three sites located several hundred meters apart, as can be seen in Fig. 1.

It includes two wind turbines $(11 \mathrm{~kW}$ and $55 \mathrm{~kW})$, a PVplant $(8 \mathrm{~kW})$, a diesel gen-set $(48 \mathrm{~kW} / 60 \mathrm{kVA})$, an intelligent office building with controllable loads (up to $20 \mathrm{~kW}$ ), a number of loads $(75 \mathrm{~kW}, 3 * 36 \mathrm{~kW})$ and a Vanadium Battery of 15 $\mathrm{kW} / 180 \mathrm{kWh}$. At each of the three sites there is a switchboard that allows the components installed at the site to be connected to either of two bus bars. 


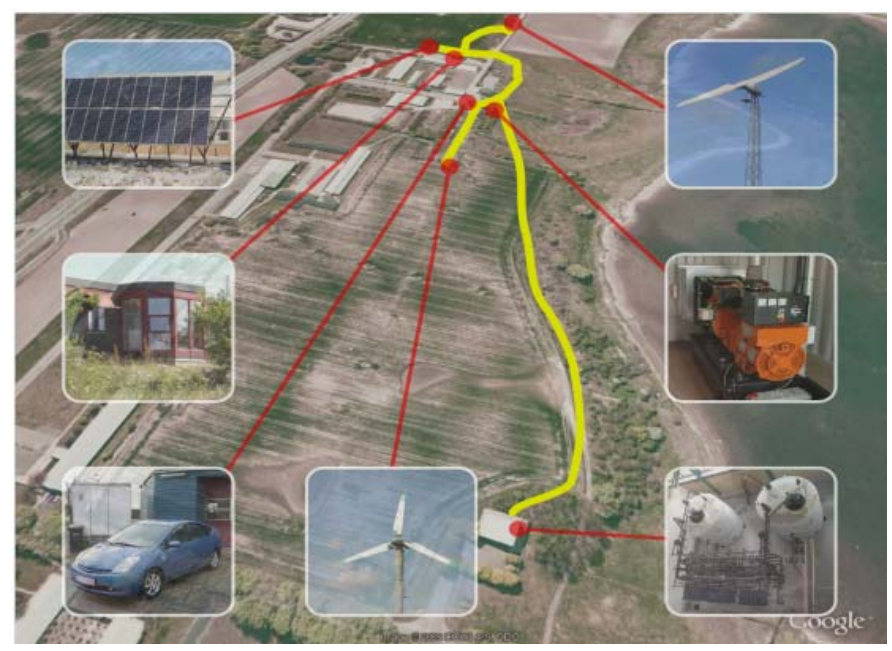

Fig. 1. SYSLAB Risø's new laboratory for intelligent, active and distributed power systems.

The two bus bars at each site are connected to a crossbar switchboard allowing the flexible setup of the system(s) to be studied. The bus bars can be either connected to the national grid or can be part of an isolated system. It allows components and systems to be in grid connected operation, island operation, or operation in parallel with wind turbine or PV-plant.

The components are all connected in one distributed control and measurement system that enables very flexible setup with respect to experimental configuration.

\section{DER COMPONENTS WITH STORAGE DEVICES AND (CONTROLlaBle) LOADS}

The system under tests contains a Diesel Gen-set of 60 $\mathrm{kVA} / 48 \mathrm{~kW}$, a GAIA Wind Turbine of $11 \mathrm{~kW}$, a Dump-Load of $75 \mathrm{~kW}$, a Vanadium-Redox Battery (VRB) of $15 \mathrm{~kW} / 180$ $\mathrm{kWh}$, and a local grid.

All units on the grid - generators, loads, storage systems, switchgear - are automates and remote-controllable. Each unit is supervised locally by a dedicated controller node. The node design combines an industrial PC, data storage, measurement and I/O interfaces, backup power and an Ethernet switch inside a compact, portable container. All nodes are interconnected via redundant high speed Ethernet, in a flexible setup permitting on-line changes of topology and the simulation of communication faults.

\section{A. Wind Turbine}

The GAIA Wind Turbine has $11 \mathrm{KW}$ rated power, 2 bladed horizontal axis, stall controlled; Rotor diameter has $13 \mathrm{~m}$, rotor speed is keep constant at $56 \mathrm{rpm}$ with a gear box ratio of 1:18. Starting wind speed is $2.5 \mathrm{~m} / \mathrm{s}$, cut in wind speed is $3.5 \mathrm{~m} / \mathrm{s}$, rated wind speed is $9.5 \mathrm{~m} / \mathrm{s}$ and cut out wind speed is $25 \mathrm{~m} / \mathrm{s}$ [10]. The machine driven by wind turbine is a cage rotor induction generator with rated power of $11 \mathrm{KW}$, rated speed of $970 \mathrm{rpm}$, rated voltage of $400 \mathrm{~V}$ and rated current of 21.8/12.7 A; It has also a capacitor bank of $10 \mathrm{kVAr}$ for self-excitation and no-load compensation. The consumption of reactive power at no load is $6.32 \mathrm{kVAr}$ and at full load is $9.7 \mathrm{kVAr}$.
It has a soft starter in order to reduce the inrush current during connection. The maximum cut-in current controlled via soft starter is $22 \mathrm{~A}$, and also max starting current is $30 \mathrm{~A}$;

\section{B.Diesel GENSET}

Diesel Gen-set contains a diesel engine with 6 cylinders, a speed governor and a synchronous generator with an AVR (automatic voltage regulator) and an AGC (automatic gen-set controller).

The governor and the diesel engine system control the generator speed and provide mechanical power as an input to the generator. Speed governing is dedicated to generator response to load changes.

The synchronous machine is a four pole machine with salientpole design. It uses brushless excitation and a digital automatic voltage regulator (AVR controller). The AVR controller regulates the parameters of exciter field to provide a constant terminal voltage. AVR acts upon the DC Voltage that supplies the excitation winding of SGs. The variation of field current in the SGs increases or decreases the emf (no load voltage) and thus for given load the generator voltage is controlled.

\section{C.PV Inverter}

$48^{\text {th }} \mathrm{PV}$ panels of around $8 \mathrm{~kW}$ are connected to the SYSLAB grid through a three-phase PV inverter (SMA Sunny Tripower). The PV inverter has the ability to provide active and reactive power regulation.

PV controller can be programmed to automatically regulate the active power at frequency deviations and the reactive power at line voltage deviations when SYSLAB is operated in isolated mode and also grid connected one.

\section{Data Acquisition and Control System}

The data acquisition and control system (hardware and software) is responsible for the supervision and control of the research platform for distributed intelligent energy systems with a high penetration of renewable energy. The supervisory software code was written in Java and is able to manage the data acquisition, processes the data and executes the control loop and outputs the control variables. The sensors outputs are connected to a signal conditioning board, which in turn is connected to the data acquisition (DAQ) board based on a PC (SCADA System).

Some loads can be controlled by the central building controller which receives data and events from wireless switches and sensors. In one room, a small touch-screen user interface can be used to influence the controller policy (Fig. 2). Through its own grid control node, the building controller can get information on the status of the power grid, and adapt its control strategy accordingly. Active policies, measurement data and user settings can be communicated back to the grid.

A dedicated controller node is collocated with each of the components.

This work was supported in part by the E.U. Project No. 228449/2011. 


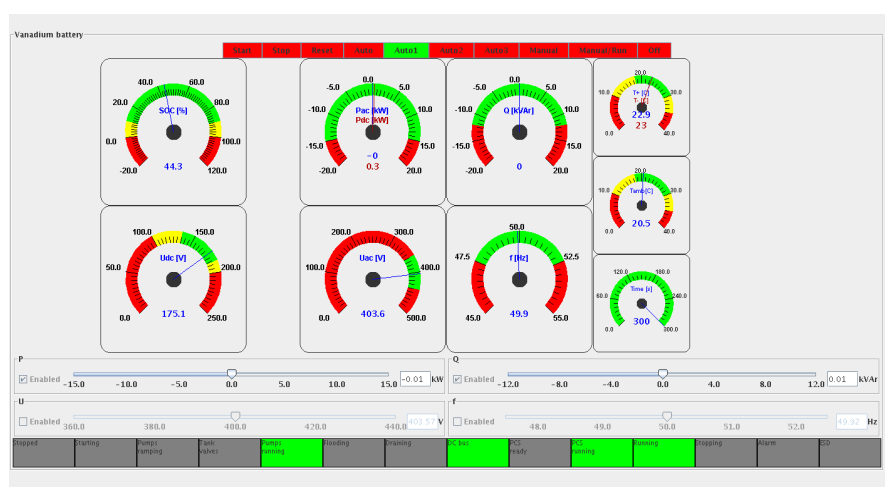

Fig. 2. Graphical user interface for control system.

\section{E.Storage Devices}

The system under tests contains also a number of loads (75 $\mathrm{kW}, 3 \times 36 \mathrm{~kW})$, an intelligent office building with controllable loads and a Vanadium Flow Battery of $15 \mathrm{~kW} / 180 \mathrm{kWh}$ as a part of the distributed energy systems experimental facility.

A vanadium battery stores energy in two electrolytes. The capacity of the battery is determined by the size of the tanks and its power is determined by the size of the cell stack. The Vanadium Redox Battery (VRB) uses different ionic forms of Vanadium in a dilute sulphuric acid for both half cells, eliminating the possibility of cross contamination. The two acid electrolytes are separated from each other by a PEM (Proton Exchange Membrane). The different redox couples are $\mathrm{V}_{5}^{+}$ $\left(\mathrm{VO}_{2}{ }^{+}\right)$and $\mathrm{V}_{4}{ }^{+}\left(\mathrm{VO}_{2}{ }^{+}\right)$for the positive half-cell and $\mathrm{V}_{3}^{+}$and $\mathrm{V}_{2}{ }^{+}$ions for the negative half-cell. At discharge the negative half-cell $\mathrm{V}_{2}{ }^{+}$is oxidized to $\mathrm{V}_{3}{ }^{+}$. The freed electron passes through the circuit and participates in the reduction of $\mathrm{VO}_{2}{ }^{+}$to $\mathrm{VO}_{2}^{+}$. During charge the reaction occurs in the opposite direction [8].

The open cell voltage is $1.4 \mathrm{~V}$ at $50 \%$ SOC (state of charge) and $1.6 \mathrm{~V}$ at $100 \%$ SOC. By power electronics the DC voltage is transformed to $400 \mathrm{~V}_{\mathrm{AC}}$. The supplier of the vanadium battery specifies high efficiencies $(>70 \%)$ and long cycle life (more than 13000 cycles for the battery). Also, it should not degrade under prolonged periods of discharge [8].

The battery package is an interesting option for storing excess energy from the hybrid grid (wind intermittency) for later use. It may also act as a peak shaving unit and thereby contribute to a stronger grid [11-13].

The propose of the energy storage system is to be coupled with a wind generation system in order to realize different tasks, such as: to have the generation output power smoothed and to grant no power transfer, for a certain period on distribution system operator request, at a point of common coupling (PCC) in any battery state of charge condition. The idea is to control the battery charging and discharging in order to control the whole power plant.

\section{COMPONENT TESTING UNDER DifFERENT MODES OF OPERATION}

The testing reported here include three modes of operation: stand alone, parallel/hybrid and grid connected.

In order to find out the differences between DER components in power systems and to study the impact on bus bar voltage and frequency the system will be tested for different wind speeds and loads.

To test the static and dynamic characteristics of a VRB a set of charge/discharge tests and a step response tests at different SOC levels have been done. The proposed tests have been carried out to characterize the battery from a power system point of view and to assess it with respect to integration of wind energy in power system and to evaluate its potential role in the future energy systems. Also the tests have been done to find the main parameters of the battery and to test the system response for parameter tuning of the controller.

\section{A. Stand-Alone Operation}

In this mode of operation the Diesel Gen-set is connected together only with a dump load, as can be seen in Fig. 1 .

The voltage and frequency are controlled by the gen-set and the load is provided by diesel generator. The ability of the diesel generator to respond to frequency changes is affected by the inertia of the Diesel Gen-set, the sensitivity of governor and the power capability of the Diesel Engine and Synchronous Generator. The response time of AVR and excitation system will show the ability of the machine to control the voltage.

The objective of the test is to investigate static and dynamic stability that means the property of the synchronous generator to remain in synchronism at a very slow and quick variation of load and to test the system response for parameter tuning of the AVR and governor controllers.

In Fig. 4 the diesel gen-set was running and at $\mathrm{t}=1 \mathrm{sec}$ has been applied a large step in load (about $80 \%$ of nominal load) from zero to $40 \mathrm{~kW}$ and back to zero at $\mathrm{t}=7 \mathrm{sec}$. The droop voltage was about $10-12 \mathrm{~V}$ and the settling time around $3 \mathrm{sec}$.

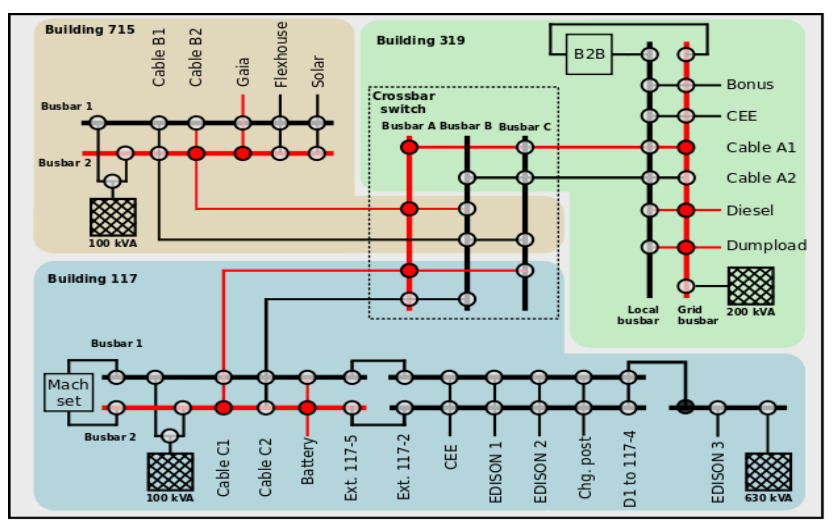

Fig. 3. Details about SYSLAB Micro-Grid architecture (plant components) in islanding mode. 


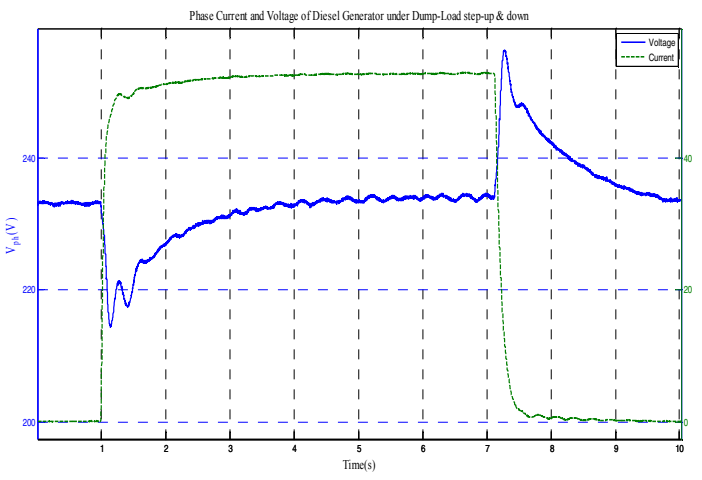

Fig. 4. Phase Voltage and Current as a function of time during switch-on and off of a large step in load. The data was acquired by an Oscilloscope with a sampling frequency of $1 \mathrm{kHz}$.

\section{B. Hybrid/Parallel Mode}

In this mode of operation the Diesel Gen-set is connected together with GAIA Wind Turbine, a dump load and a battery. The voltage and frequency are controlled by the gen-set and the load is shared between DG and Gen-set.

The main objective of the tests has been to study the voltage, active and reactive power and frequency and speed variations during variable wind conditions and during start-up and shut-down of the wind turbine and during changes in load.

Another objective was to investigate if the Gen-set unit maintains synchronism during these transients. This includes the dynamic performance (Fig. 5) and the long term conditions, too (Fig. 6).

In Fig. 5 is depicted a start-up sequence of GAIA Wind Turbine at a wind speed higher than nominal $(w s=12 \mathrm{~m} / \mathrm{s}>$ $w s_{N}=9.5 \mathrm{~m} / \mathrm{s}$ ), with the Diesel Gen-set and a load of $12 \mathrm{~kW}$ already connected (see Fig. 3). The GAIA WT was connected at $\mathrm{t}=1 \mathrm{sec}$, then a step-up in load was applied at $\mathrm{t}=4 \mathrm{sec}$ and a step-down at $\mathrm{t}=7 \mathrm{sec}$ from $15 \mathrm{~kW}$ to $20 \mathrm{~kW}$. During these changes in load the voltage response of the synchronous generator controller was very fast. The droop voltage was the same as in standalone operation when we applied a large step in load but the settling time in this case was larger (about 4 $\mathrm{sec})$. Also the current has risen from $18 \mathrm{~A}$ to $42 \mathrm{~A}$.

In Fig. 5b) is shown the voltage response when the GAIA Wind Turbine was disconnected with Diesel Generator and a load of around $12 \mathrm{~kW}$ still connected.

The Figures 6-7 presents the dynamic performance of the system in terms of active and reactive power distribution between the components and voltage, frequency and speed response of the system during different transient, such as connection and disconnection of the wind turbine, and during a large step in load.

The variations in wind turbine output are compensated by diesel gen-set. The voltage and frequency variations are very small during dynamic changes due to the automatic voltage regulator (AVR) of the synchronous machine exciter and speed governor of the diesel engine. The frequency variations are between $(49 \div 51) \mathrm{Hz}$ and speed variations are between $(1480 \div 1520)$ rpm, as can also be seen in Fig. 6. In Fig. 7 the battery was used as a load with GAIA wind turbine and Diesel Gen-set connected together.

Frequency band of AVR controller is within 2-3 Hz and of speed governor control is less than $2 \mathrm{~Hz}$, in general. SGs operating in a power system have speed droop controllers to allow for power sharing between various units. Speed droop is typically (4-5) \% [9].

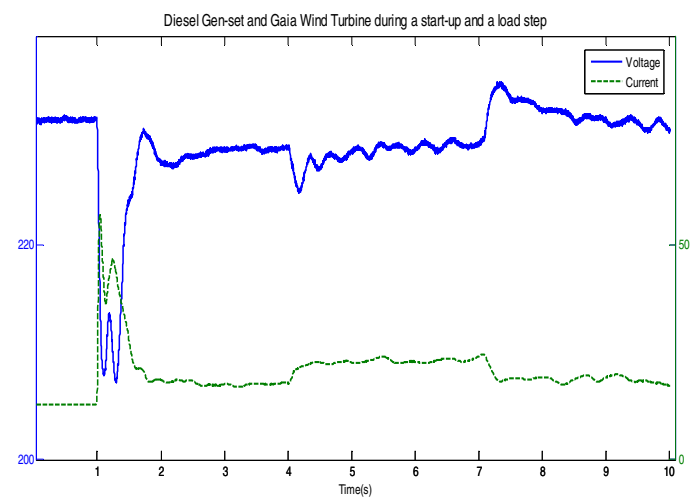

a)

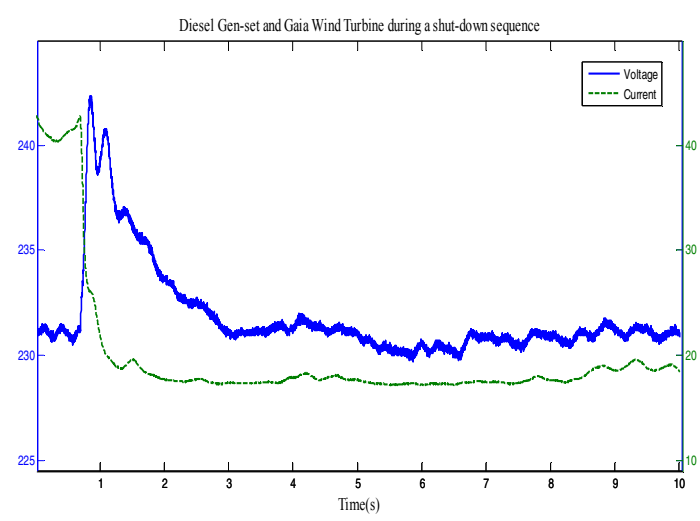

b)

Fig. 5. Phase current and voltage acquired by an Oscilloscope a) when the wind turbine was connected at $1 \mathrm{sec}$ and an increase and a decrease step in load was applied at 4 and $7 \mathrm{sec}$. respectively, and b) during a shut-down sequence. The GAIA was connected together with the Diesel Gen-set and a dump load.

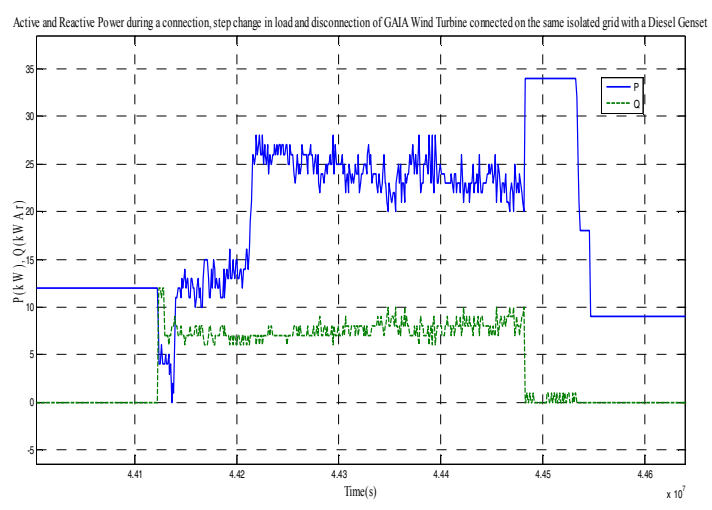

a) 

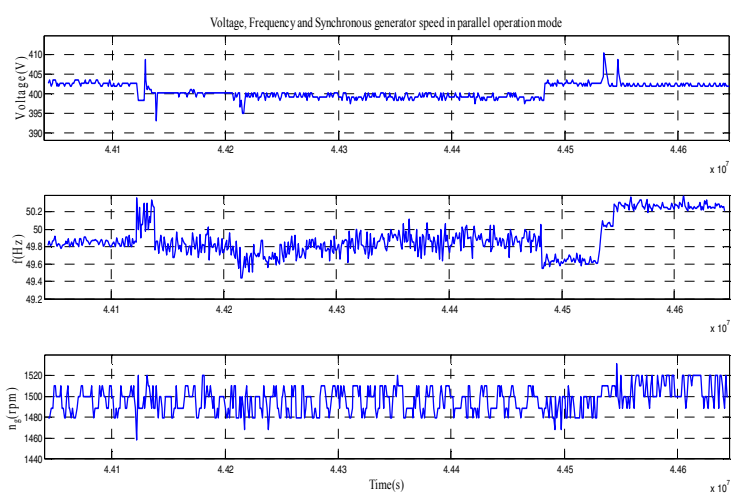

b)

Fig. 6. a) Active and reactive power and b) voltage, frequency and speed as a function of time when the Gaia WT was connected together with Diesel GenSet and a battery $(\mathrm{t}=4.41 \mathrm{sec})$, then a step in load was applied at $\mathrm{t}=4.42 \mathrm{sec}$ and the GAIA was disconnected at around $\mathrm{t}=4.45 \mathrm{sec}$.
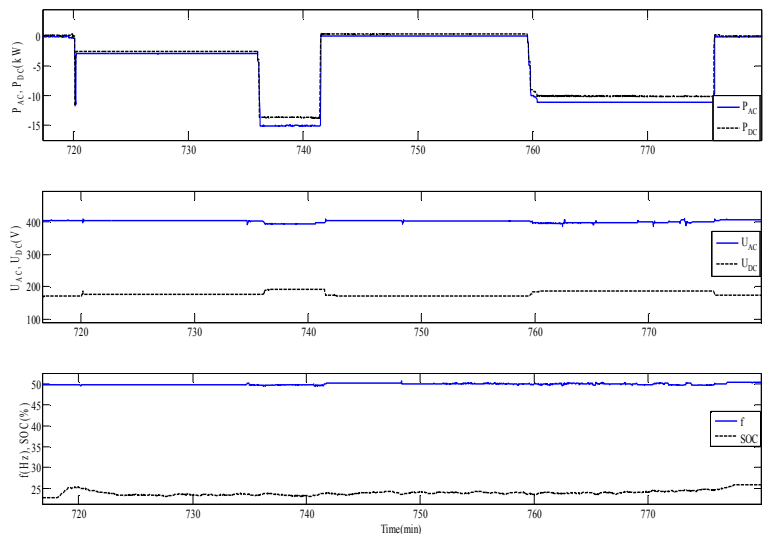

Fig. 7. AC and DC Power and Voltage, SOC level and Frequency of the battery terminals when the GAIA Wind Turbine was connected $(t=720$ $\mathrm{min}$ )/disconnected ( $\mathrm{t}=775 \mathrm{~min})$ to/from the hybrid system and a step in load was applied at $738 \mathrm{~min}$ and again at $760 \mathrm{~min}$.

\section{Grid Connection}

In this mode of operation the GAIA Wind Turbine was connected to the local grid together with a Vanadium Battery. The main objective of the tests has been to study the active power and generator speed variations during variable wind conditions and during start-up and shut-down of the wind turbine.

During the start-up sequence the current of the induction generator increased 3 times more than nominal current $\left(\mathrm{i}_{\mathrm{N}}=22\right.$ A) and the start-up time was around 2 second, as shown in Fig. $8 \mathrm{a})$. The wind speed was between $10-15 \mathrm{~m} / \mathrm{s}$ and the active power produced by wind turbine between $9-12 \mathrm{~kW}$, as can also be seen in Fig. 8b).

In Fig. 9 is shown a dynamic response test of VRB during charge/discharge cycle and a step response test at different SOC levels. The battery-inverter system can function as a power source when it is discharging energy, and as a load as it is storing energy.

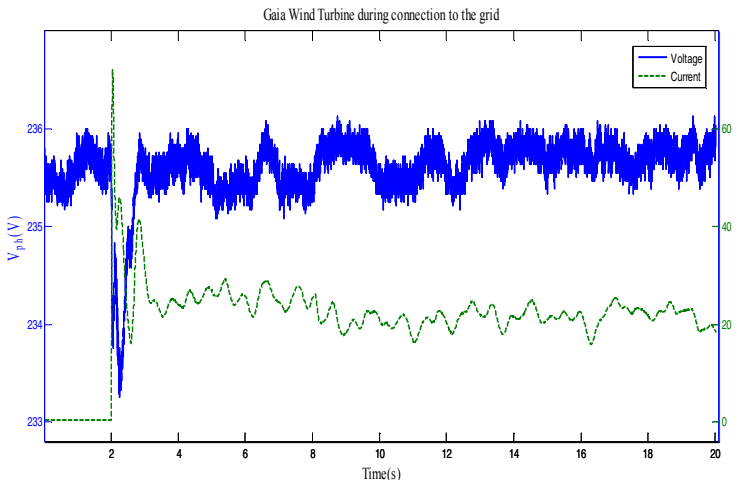

a)
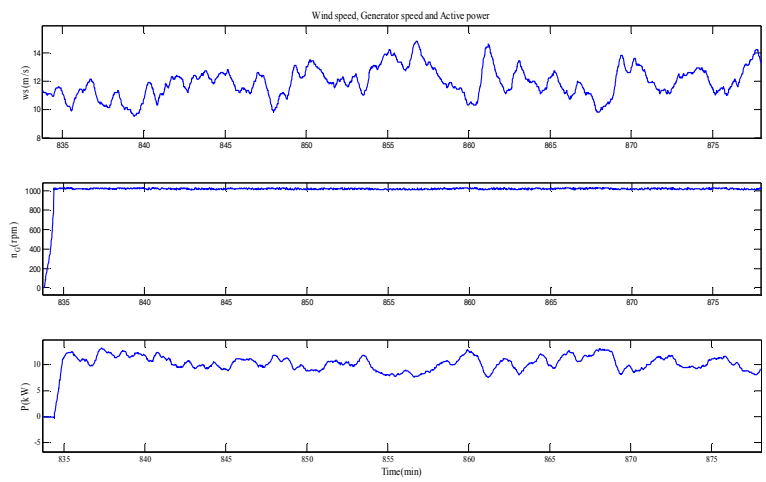

b)

Fig. 8. a) Generator Phase Voltage and Current during a start-up sequence to the local grid, acquired by an Oscilloscope and b) Wind, Generator Speed and Active Power, acquired by SCADA system with a sampling frequency of $1 \mathrm{~Hz}$.
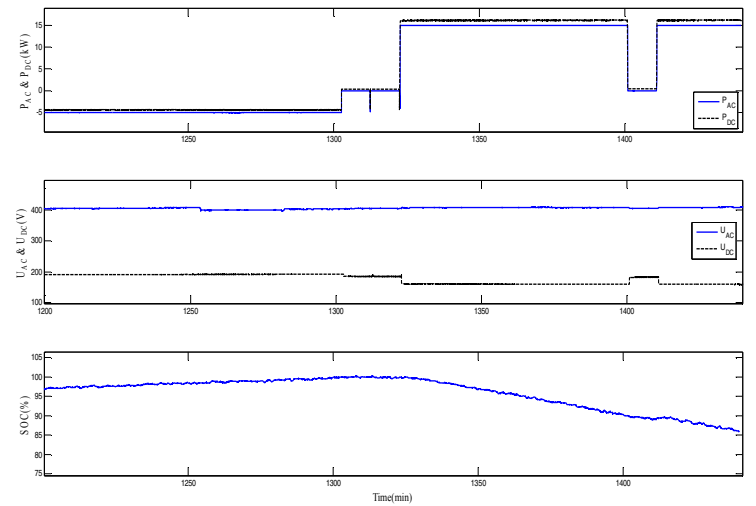

Fig. 9. AC and DC Power and AC and DC Voltage during a charge/discharge cycle at different SOC levels. The data was acquired by SCADA System at battery terminals.

\section{DISCUSION AND CONCLUSION}

The modeling of DER components in power systems and the relative control architecture are an important part for the introduction of relevant quantity of renewable energy in the future smart grid. Therefore it is a strong necessity to have proper validated models to help operators to perform better studies and to be more confident with the results. 
In order to find out the parameters of various types of DER components for dynamic simulation models a number of tests are required under different operation modes and loads. It is essential to find generic parameters and the approach to obtain their values in order to facilitate the modeling of a system. Effects of static and dynamic stability, effects of disturbances on power system equipment and network should be analyzed.

AC power system satisfactory operation is obtained when frequency and voltage remain nearly constant or vary in a limited and controlled manner when active and reactive loads vary. Active power flow is related to prime mover's energy input and thus to the speed of synchronous generator. On the other hand, reactive power control is related to terminal voltage. When a generator acts alone on a load, or it is by far the strongest in an area of a power system, its frequency may be controlled via generator speed, to remain constant with load. Integration of a diesel gen-set in an isolated power system can improve the system behavior during large changes in load.

Automatic generation control (AGC) distributes the generation task between AVR controller and speed governor. Speed (frequency) control quality depends on the speed control of the SG but also on the other induced influences, besides the load dependence on frequency. SG voltage control quality depends on the SG parameters and excitation power source dynamics.

The battery package is an interesting option for storing excess energy from the hybrid grid (wind intermittency) for later use. It may also act as a peak shaving unit and thereby contribute to a stronger grid.

A series of tests has been done for different operational scenarios and during several modes of operations to find out the parameters for dynamic modeling of DER components in power systems and also to implement and test different control strategies for the combined system.

Moreover to point out, on a laboratory scale, the coupling between wind generation and storage and to effectively compensate wind fluctuations a number of tests have been done during charge/discharge cycles.

A suitable model for SYSLAB Micro-Grid will be develop and implemented in the dedicated simulation tool PowerFactory and the parameters used for DER components will be based on the measurements and tests reporting in this paper.

\section{REFERENCES}

[1] H. Jiayi, J. Chuanwen and X. Rong, "A review on distributed energy resources and MicroGrid," ELSEVIER, Renewable \& Sustainable Energy Reviews, vol. 12, pp. 2472-2483, 2008.

[2] J. M. Guerero, J.C. Vasquez, J. Matas, J.L. Sosa and L.G. de Vicuna, "Parallel Operation of Uninterruptible Power Supply Systems in MicroGrids", IEEE Transactions on Industrial Electronics, vol. 55, no. 8, August 2008, pp. 2845-2856.

[3] W. Pan, W. Gao and E. Muljadi, "The Dynamic Performance and Effect of Hybrid Renewable Power System with Diesel/Wind/PV/Battery", IEEE Transaction on Industry Applications, vol. III, 2010, pp. 1-6.

[4] B. Sedaghat, A. Jalilvand and R. Noroozian, "Design of a Predictive Control Strategy for Integration of Stand-Alone Wind/Diesel System", Procedings of IEEE Internation Conference on Power and Energy, November 29-December 1, Kuala Lumpur, Malaysia, 2010.

[5] IEEE Standard for Interconnecting Distributed Resources with Electric Power Systems, IEEE Std. 1547, 2008.

[6] IEEE Guide for Synchronous Generator Modeling Practices and Applications in Power System Stability Analysis, IEEE Std 1110-2002.

[7] B. Kroposki, T. Basso and R. DeBlasio, "Interconnecting Testing of Distributed Resources", IEEE 1547-2003, Standard for Distributed Resources Interconnected with Electric Power System, July 2003.

[8] H. Bidner, C. Ekman, O. Gehrke and F. Isleifsson, "Characterization of Vanadium Flow Battery",Riso-R-1753 Report, Roskilde, Denmark, October 2010.

[9] I. Boldea, "The Electric Generators Handbook" CRC Press, USA 2006, ISBN 084931481X.

[10] H. Bindner, P.A.C. Rosas, R. Teodorescu and F. Blaabjerg, "Stand-alone version of the $11 \mathrm{~kW}$ Gaia wind turbine", Riso-R-1480, RoskildeDenmark, September 2004.

[11] N. Gyawali, Y. Ohsawa and O. Yamamoto, "Power Dispatching from Cage Induction Generator Based Wind Power System with Integrated Smart Energy Storage", IEEJ Transactions on Electrical and Electronic Engineering, vol. 6, pp. 134-143, 2011.

[12] A. Karthikeyan, C. Nagamani, G. Saravana Ilango and A. Sreenivasulu, "Hybrid open-loop excitation system for wind turbine-driven standalone induction generator", IET Renewable Power Generation Journal, vol. 5 , iss. 2, pp. 184-193, 2011.

[13] L. Barote, R. Weissbach, R. Teodorescu, C. Marinescu, M. Cirstea, "Stand-Alone Wind System with Vanadium Redox Battery Energy Storage", IEEE, International Conference on Optimization of Electrical and Electronic Equipments, OPTIM'08, pp. 407-412, 22-24 May 2008, Brasov, Romania.

[14] I. Bae and J. Kim, "Reliability evaluation of customers in a microgrid", IEEE Transaction on Power Systems, vol. 23, no. 3, pp. 1416-1422, August 2008 .

[15] A. Tsikalakis and N. Hatziargyriou, "Centralized control for optimizing microgrids operation", IEEE Transaction on Energy Conversions, vol. 23, no. 1, pp. 241-248, March 2008. 